\title{
Oncoplastic Breast Surgery after Neoadjuvant Chemotherapy Replacing Mastectomy in Locally Advanced Breast Cancer (LABC): Single Institute Experience
}

\author{
Yasser El Ghamrini1 ${ }^{*}$, Ahmed Morad ${ }^{1}$, Hossam Elsadek ${ }^{1}$, Ahmed Ezzat ${ }^{2}$ \\ ${ }^{1}$ General Surgery Department, Ain Shams University, Cairo, Egypt \\ ${ }^{2}$ Clinical Oncology Department, Ain Shams University, Cairo, Egypt \\ Email: ^Yassermohamed.eg84@yahoo.com
}

How to cite this paper: El Ghamrini, Y., Morad, A., Elsadek, H. and Ezzat, A. (2017) Oncoplastic Breast Surgery after Neoadjuvant Chemotherapy Replacing Mastectomy in Locally Advanced Breast Cancer (LABC): Single Institute Experience. Journal of Cancer Therapy, 8, 1058-1067.

https://doi.org/10.4236/jct.2017.811090

Received: October 24, 2017

Accepted: November 25, 2017

Published: November 28, 2017

Copyright $\odot 2017$ by authors and Scientific Research Publishing Inc. This work is licensed under the Creative Commons Attribution International License (CC BY 4.0).

http://creativecommons.org/licenses/by/4.0/ (c) (i) Open Access

\begin{abstract}
Background: Integration of neoadjuvant chemotherapy (NCT) in early 70 s resulted that many LABC tumors become resectable but with total mastectomy especially those with partial response, oncoplastic techniques give better oncological outcome with better cosmetic results. Objective: We evaluate the oncological safety of oncoplastic breast surgery (OS) in LABC showing partial response to NCT. Methods: We prospectively analyzed the data of 32 out of 58 patients with LABC who showed partial response to NCT and could have conservative surgery with advanced oncoplastic techniques rather than total mastectomy. Results: Out of 58 patients with LABC, received neoadjuvant chemotherapy, complete response was observed in 8 patients (13\%), partial response reported in $32(55.1 \%)$ cases, 12 patients $(20 \%)$ had stable disease and 6 patients $(10 \%)$ showed progressive disease. Data of 32 cases were studied (mean age $44.84 \pm 9.10$ years; range 26 - 59 years). Inferior pedicle was performed in 9 cases, mini LD flap in 3 patients, 5 had Grissotti technique, 6 with superomedial pedicle, 4 had $\mathrm{V}$ mammoplasty and 3 with $\mathrm{J}$ mammoplasty and 2 had vertical mammoplasty. Margins were positive in 5 cases (15.6\%) with mean margin width $9.63 \pm 5.72$ (range $0-22 \mathrm{~mm}$ ), and the local recurrence was reported in 2 cases (6.2\%). Complications were reported in 3 cases (9.3\%). The follow up was $1.67 \pm 1.03$ (range 0 - 3.3 years). Conclusions: Integration of neoadjuvant chemotherapy together with advanced oncoplastic techniques opens a new way for management of LABC especially those showing partial response with avoidance of total mastectomy, and comparable oncological safety in addition to better aesthetic and psychological outcome.
\end{abstract}

\section{Keywords}

Locally Advanced Breast Cancer, Oncoplastic Surgery, Oncological Safety, 


\section{Introduction}

LABC is a common presentation in females with breast cancer in the developing countries with incidence $(20 \%-25 \%)$ [1]. It is defined clinically as tumors $>5 \mathrm{~cm}$, fixed to the skin, underlying muscles or chest wall and or fixed axillary lymph nodes [2]. The American Joint Committee on Cancer (AJCC) categorized LABC as stage III which could be IIIA (T0N2M0; T1/2N2M0; T3N1/2M0), stage IIIB (T4N0-2M0), and stage IIIC (TanyN3M0) [3].

Total mastectomy was the only surgical management for resectable LABC, till the evolving of the era of down staging by chemotherapy before surgery which termed neoadjuvant chemotherapy (NCT) [4] [5]. Furthermore it gives a good control to micrometastasis in early stage thus stopping the unpredictable behavioral changes that occur in the metastatic cells [6] [7].

Unfortunately, some patients give partial response to NCT with only $30 \%$ decrease in tumor size according to RECIST (Response Evaluation Criteria in Solid Tumors), created in 90s [8].

Accordingly, there is no substitute other than mastectomy. However in mid 90s Audretsch firstly described the term of oncoplastic breast surgery in which plastic techniques integrated with oncological procedures giving wide resection with more oncological safety and better cosmetic results [9].

Different techniques were described ranging from simple glandular reshaping to advanced mammoplasty techniques which were described by Clough et al. as level 2 oncoplasty in which up to $50 \%$ of the breast volume could be resected without compromising the aesthetic results [10].

The aim of this study is to evaluate the oncological safety of oncoplastic surgery in LABC patients after neoadjuvant chemotherapy especially those with partial response.

\section{Patients and Methods}

\subsection{Patients Selection}

This planned study was conducted on 58 female patients during the period from January 2012 to February 2013 who presented to our tertiary referral breast unit at Ain Shams University Hospitals with locally advanced breast cancer stage IIIA, IIIB and IIIC according to AJCC staging system and decision was taken to receive neoadjuvant chemotherapy after approval of the ethical committee held in September 2011.

Inclusion criteria were patients with age range between 25 and 60 years old, performance status $\leq 2$, pathologically proven invasive ductal or lobular carcinoma, left ventricular ejection fraction by Echocardiography more than $55 \%$. We excluded pregnant and lactating patients, those with second or previous malig- 
nancy, patients with multicenteric tumors, those for palliative wide local excision and patients contraindicated for chemotherapy due to comorbidities. We selected those who showed partial response to NCT (32 patients) for oncoplastic techniques for tumor resection and excluded who showed poor response to neoadjuvant chemotherapy, and those with progressive or complete pathological response (26 patients).

\subsection{Pre-Treatment Evaluation}

All patient diagnosed by clinical examination, bilateral breast ultrasound and mammography with assessment of tumor size before and after NCT clinically and radiologically. Pathological diagnosis done by ultrasound guided core biopsy with determining of the hormonal status. The estrogen (ER) and progesterone receptor (PR) status and HER 2 neu expression were assessed by immunohistochemical and FISH or SISH if needed with evaluation of ki67.

Tumors considered hormone positive if more than $10 \%$ of cells stain for estrogen and progesterone receptors and Her-2 positive with score +3 .

Metastatic work up done routinely for all cases (pelvi-abdomen and chest CT with bone scan). ECHO, electrocardiography and estimation of EF.

All cases were discussed in our (M.D.T) including clinical oncologist, breast surgeons, radiologist and pathologist. The demographic and pathological data of all patients were shown in Table 1.

The histological type of the tumor, the size of the invasive component, the grade of the tumor and the positive number of lymph nodes were all recorded. In addition to resected specimens weight, margin status and length (Table 2).

\subsection{Neoadjuvant Chemotherapy}

All eligible patients received neoadjuvant chemotherapy before surgery in the form of anthracycline combination ( 4 cycles AC) i.e. adriamycin $60 \mathrm{mg} / \mathrm{m}^{2} \mathrm{I}$.V. on day 1 and cyclophosphamide $600 \mathrm{mg} / \mathrm{m}^{2} \mathrm{I}$.V day 1 . Cycles repeated every 21 days for 4 cycles followed by paclitaxel $80 \mathrm{mg} / \mathrm{m}^{2}$ by I.V. infusion weekly for $12 \mathrm{wks} \pm$ Trastuzumab $6 \mathrm{mg} / \mathrm{kg}$ every 3 weeks according to the Her 2 stains. CBC and blood chemistry were done before each cycle.

Assessment of tumor response was done routinely after $2^{\text {nd }}$ cycle and each 2 cycles using by clinical examination and breast imaging according to RECIST criteria. Patient response is shown in Table 3.

\subsection{Surgical Techniques}

All patients in the study had level 2 oncoplasty by the same surgical team. Preoperative marking done in the clinic day before surgery. Five cases had Grissotti technique for centrally located tumors, 3 with mini L.D flap after Upper outer quadrantectomy, 9 patients had inferior pedicle for upper pole tumors, 6 cases with superomedial pedicle for lower pole tumors, vertical mammoplasty done in 2 cases, 4 patients had $\mathrm{V}$ mammoplasty for lower inner quadrant tumors and 3 
Table 1. Demographic and tumor characteristics among the studied group operated by oncoplastic surgery.

\begin{tabular}{|c|c|c|}
\hline & & No. $=32$ \\
\hline \multirow{2}{*}{ Age } & Mean \pm SD & $44.84 \pm 9.09$ \\
\hline & Range & $26-59$ \\
\hline \multirow{6}{*}{ Site } & Central & $5(15.6 \%)$ \\
\hline & Inferior pole & $4(12.5 \%)$ \\
\hline & LIQ & $5(15.6 \%)$ \\
\hline & LOQ & $3(9.4 \%)$ \\
\hline & UOQ & $10(31.2 \%)$ \\
\hline & Upper pole & $5(15.6 \%)$ \\
\hline \multirow{2}{*}{ Pathology } & IDC & $26(81.2 \%)$ \\
\hline & ILC & $6(18.8 \%)$ \\
\hline \multirow{2}{*}{ Size after } & Mean \pm SD & $4.06 \pm 0.70$ \\
\hline & Range & $2.8-5.5$ \\
\hline \multirow{2}{*}{ Size before } & Mean \pm SD & $5.23 \pm 0.85$ \\
\hline & Range & $3.5-6.8$ \\
\hline \multirow{2}{*}{ ER } & Negative & $12(37.5 \%)$ \\
\hline & Positive & $20(62.5 \%)$ \\
\hline \multirow{2}{*}{ PR } & Negative & $13(40.6 \%)$ \\
\hline & Positive & $19(59.4 \%)$ \\
\hline \multirow{2}{*}{ HER-2 } & Negative & $24(75.0 \%)$ \\
\hline & Positive & $8(25.0 \%)$ \\
\hline \multirow{2}{*}{ Positive ALN } & Mean \pm SD & $5.07 \pm 2.52$ \\
\hline & Range & $2-12$ \\
\hline \multirow{2}{*}{ Total ALNC } & Mean \pm SD & $20.07 \pm 4.24$ \\
\hline & Range & $12-28$ \\
\hline
\end{tabular}

ALN: axillary lymph nodes. ALNC: axillary lymph nodes clearance.

Table 2. Characteristics of resected specimens.

\begin{tabular}{ccc}
\hline & & No. $=\mathbf{3 2}$ \\
\hline \multirow{2}{*}{ Weight } & Mean \pm SD & $233.56 \pm 186.34$ \\
& Range & $32-845$ \\
Margins & Negative & $27(84.4 \%)$ \\
& Positive & $5(15.6 \%)$ \\
Mean length & Mean \pm SD & $9.63 \pm 5.72$ \\
& Range & $0-22$ \\
\hline
\end{tabular}

patients had J mammoplasty for lower outer quadrant tumors.

SLNB was done in two cases only with negative axilla (clinically and/or radiologically) before starting NCT, while the other cases $(n=30)$ had formal axillary clearance (level 1,2). 
Table 3. Response to neoadjuvant chemotherapy.

\begin{tabular}{cc}
\hline Response & $\mathbf{5 8}$ patients $\mathbf{~}(\%)$ \\
\hline SD & $12(20 \%)$ \\
PD & $6(10 \%)$ \\
CR & $8(13 \%)$ \\
PR & $32(55.1 \%)$ \\
\hline
\end{tabular}

Intraoperative frozen section for the margin status done in all cases with utilization of $2 \mathrm{~mm}$ as a cut-off value ( $\geq 2 \mathrm{~mm}$ means negative margins).

Intraoperative clipping of the tumor bed with metal clips done in all cases to facilitate radiotherapy, 2 separate drains were used for axilla and tumor bed.

Contralateral symmetrisation was done in 15 cases.

\subsection{Adjuvant Therapy}

Adjuvant therapy may involve completion of chemotherapy cycles as already planned if not completed preoperatively. Postoperative radiation to the chest well in case of MRM or to the breast in case of oncolplastic surgery + lymph nodes irradiation, hormone therapy whether tamoxifen or aromatase inhibitor was given to patients according to hormone receptors status. Trastuzumab was given for Her2 new positive patients for a total one year duration.

\subsection{Follow up Protocol}

History and physical examination every 3 months with annual mammography (Figure 1).

\section{Results}

The patient age range from (26 - 59) years old (mean $44.8 \pm 9.10$ ), family history was positive in 6 patients (18.8\%).

Thirty two patients (55.1\%) had partial response, 8 patients (13\%) showed complete response, stable disease reported in 12 patients (20\%) and progressive disease in 6 patients (10\%).

Twenty six patients (81.2\%) with IDC and 6 patients (18.8\%) had ILC. 65.6\% of the tumors were nuclear grade (3), $34.4 \%$ were grade (2), ER was positive in 20 cases (62.5\%), 19cases (59.4\%) show PR positive stain, Her-2 was positive in 8 patients $(25 \%),(12.5 \%)$ had triple negative tumors, margins were positive in 5 cases $(15.6 \%$ ) with mean margin length $9.63 \pm 5.72$ (range $0-22 \mathrm{~mm}$ ), mean weight of resected specimens $233.56 \pm 186.34 \mathrm{gm}$ (range 38 - $945 \mathrm{gm}$ ), mean size of the tumors before NCT $5.23 \pm 0.85 \mathrm{~cm}$ (range $3.5-6.8 \mathrm{~cm}$ ) while after NCT $4.06 \pm 0.70 \mathrm{~cm}$ (range $2.8-5.5 \mathrm{~cm}$ ), Patients had mean follow up $1.67 \pm 1.03$ years (range 0 - 3.3 years), with Local recurrence reported in 2 cases $(6.2 \%)$ one of them developed also distant metastasis (bone metastasis). The mean number of positive axillary lymph node $5.07 \pm 2.5$ L.N. (range 2 - 12 L.N). Complications were reported in 3 cases (9.3\%) (one had nipple areola complex NAC necrosis, 


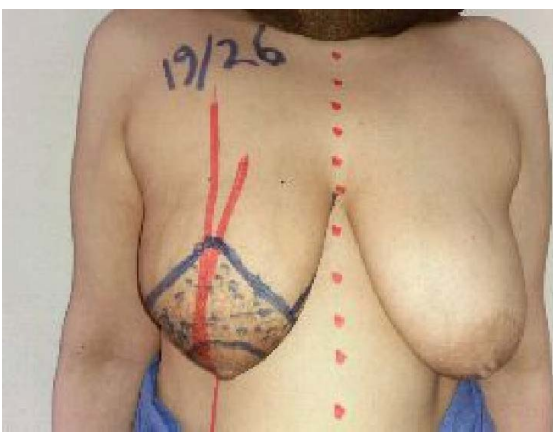

(a)

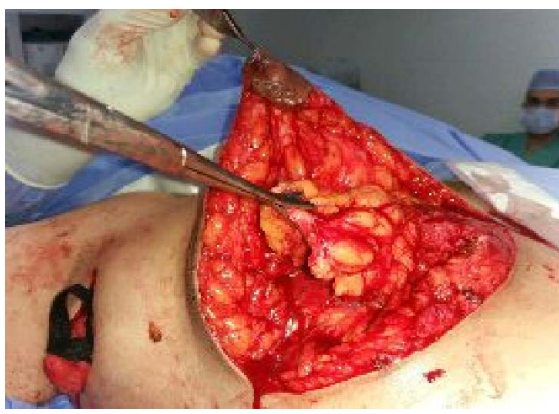

(c)

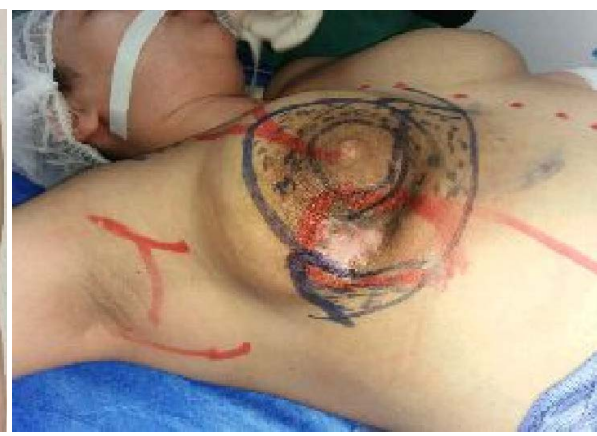

(b)

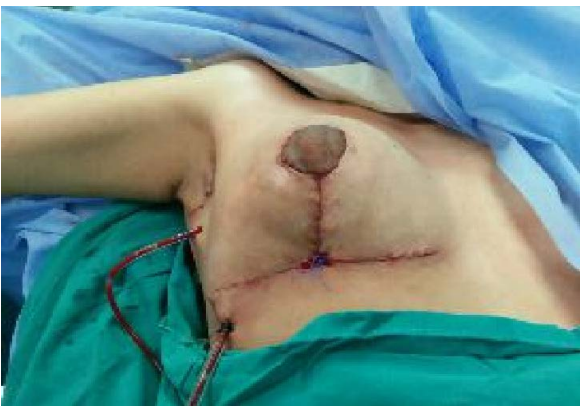

(d)

Figure 1. (a) Preoperative marking; (b) Locally advanced breast cancer in LOQ; (c) The Tumor resected with displacement by pedicled flaps; (d) Final results.

two cases with wound infection and suture disruption (one of them was diabetic) with delay in the adjuvant therapy. Complications of chemotherapy were tolerable in general. Grade 1 and 2 nausea were recorded in 50 patients (87\%) while vomiting occurred in 16 patients (27\%), alopecia grade 2 was reported in 52 patients (90\%). Grade 1 and 2 neutropenia reported in 19 patients (33\%), according to NCI-CTC v2.0 score system.

\section{Discussion}

NCT become widely accepted as standard step in management of LABC after the European institute clinical trial in the early 70 s to downstage the tumor or to convert irresectable breast cancer to operable one [11], Moreover it has the same 5 year survival and DFS as adjuvant chemotherapy [12].

However not all patients gives good or complete response after NCT, as partial response still reported and consequently wide resections are required with the overlying skin to achieve negative margins.

Standard conservative breast surgery still have limitations especially in difficult quadrants (UIQ, LIQ and central), when $>10 \%$ of breast volume had to be resected and when skin resection is required [13].

The use of oncoplastic techniques gives more options to have wide resections without compromising the oncological nor cosmetic results.

In this study we evaluate the effectiveness of oncoplastic breast surgery (OS) in patients with LABC showing partial response after NCT as substitute to total 
mastectomy [14].

We conducted a prospective study on 32 patients had oncoplastic techniques among 58 patients with LABC and received NCT, Specht and Gralow [15] reported 14 patients (25.9\%) with LABC had partial response to NCT, Viera et al. [16] published data of 26 had OS from 486 patient had NCT for LABC, In 2015 Emmanuel et al. [17] reported 29 patients with LABC operated by oncoplastic surgery among 119 cases, Also a prospective clinical trial done by Mathes et al. [18] on 17 patient with LABC treated by oncoplastic surgery. Additionally Regano et al. [19] operated 23 patients with OS after NCT.

We determined tumor size in our patients clinically and radiologically, The mean size before NCT $5.23 \pm 0.85 \mathrm{~cm}$ (range $3.5-6.8 \mathrm{~cm}$ ) And after NCT $4.06 \pm$ $0.70 \mathrm{~cm}$ (range $2.8-5.5 \mathrm{~cm}$ ), In the study conducted by Emmanuel et al. [17] the initial mean size $41.6 \mathrm{~mm}$ before and $25.3 \mathrm{~mm}$ after NCT in study on 119 patient (29 had oncoplastic surgery), Veira et al. [16] reported initial tumor size $5.26 \mathrm{~cm}$ in 26 patients with LABC underwent OS, The term extreme oncoplasty was first described by Silverstein [20] who published data on 66 patients with mean size $77 \mathrm{~mm}$.

One of the predictors for oncological safety is the margin status, we had 5 cases $(15.6 \%)$ with positive margins with mean width $9.63 \pm 5.72 \mathrm{~mm}$, In Brazil Mathes et al. [18] operated 17 patient with LABC utilizing advanced oncoplastic techniques with no positive margins, Similary Viera et al. [16] reported margin length $16.44 \mathrm{~mm}$ by oncoplastic surgery with no positive margins, Emiroglu et al. [14] found that the mean surgical margin length was $8.7 \mathrm{~mm}$ (range 5 - 17 $\mathrm{mm}$ ) with positive margins in $7.1 \%$ of cases, in a study done by Clough et al. [21] patients who received NACT and OS had a positive margins rate $10.9 \%$.

The mean follow up was 1.7 years with 2 cases had local recurrence (LR) (one had triple negative tumor and the other was Her-2+), Within 61 months follow up Emiroglu et al. [14] had 14.6\% local recurrence, Regano [19] reported 1 case with LR during 32 months follow up, 2 cases had LR within 60 months follow up in study of Viera [16], Specht and Gralow [15] reported no LR in 15 months follow up, mean follow-up was 72.8 months. Ipsilateral local and locoregional recurrence were $11.2 \%$ and $15.3 \%$ respectively in the study published by Carrrara in 2017 [13]. Clough et al. [21] had 4 years follow up with 9.5\% LR rate.

Bogusevicius et al. [22] said that six patients (10\%) had locoregional recurrence in mean follow up 86 months.

Anthracyclin based regimens were used commonly for three to four cycles till the era of Taxanes, till now no optimal duration nor approach has been established, Also the patients response vary widely as some give maximal tumor reduction within one or two cycles, in contrast other patient may require eight cycles or even more [23].

Many trials have studied the role of taxanes in neoadjuvant setting. Regimen selections varied a lot, between combination regimen and sequential, with different schedule and total number of cycles. However, the use of taxanes in neoadju- 
vant setting seems to be associated with better outcome as regards response rate ranging from $85 \%$ to $93 \%$ and pathological complete response (PCR) rates from $11 \%$ to $31 \%$ in the sequential regiments [24] [25].

In our study, we used the sequential regimen 4 cycles of $\mathrm{AC}$ followed by paclitaxel weekly for 12 weeks.

Three cases had surgical complications in our study with delay in the adjuvant therapy in 2 cases (6\%), Mazouni et al. [26] reported complications rate $16.7 \%$ but most of them were minor, Bogusevicius et al. [22] reported complication rate $5 \%$, with delay in adjuvant therapy in one case.

\section{Conclusion}

Management of LABC could be done by advanced oncoplastic surgical techniques especially for partial responders to neoadjuvant chemotherapy to avoid total mastectomy meanwhile it can yield comparable oncological results beside the psychological and cosmetic results.

\section{References}

[1] Ozmen, V., Unal, E.S., Muslumanoglu, M.E., Igci, A., Canbay, E., Ozcinar, B., Mudun, A., Tunaci, M., Tuzlali, S. and Kecer, M. (2010) Axillary Sentinel Node Biopsy after Neoadjuvant Chemotherapy. European Journal of Surgical Oncology, 36, 23-29. https://doi.org/10.1016/j.ejso.2009.10.015

[2] Yalcin, B. (2013) Overview on Locally Advanced Breast Cancer: Defining, Epidemiology, and Overview on Neoadjuvant Therapy. Experimental Oncology, 35, 250-252.

[3] American Joint Commission on Cancer (2010) Breast. In: Edge, S.B., Byrd, D.R., Compton, C.C., Fritz, A.G., Greene, F.L. and Trotti III, A., Eds., AJCC Cancer Staging Manual, 7th Edition, Springer, New York, 345-377.

[4] Makris, A., Powles, T.J., Ashley, S.E., Chang, J., Hickish, T., Tidy, V.A., Nash, A.G. and Ford, H.T. (1998) A Reduction in the Requirements for Mastectomy in a Randomized Trial of Neoadjuvant Chemoendocrine Therapy in Primary Breast Cancer (See Comments). Annals of Oncology, 9, 1179-1184. https://doi.org/10.1023/A:1008400706949

[5] Mauriac, L., MacGrogan, G, Avril, A., Durand, M., Floquet, A., Debled, M., Dilhuydy, J.M. and Bonichon, F. (1999) Neoadjuvant Chemotherapy for Operable Breast Carcinoma Larger than $3 \mathrm{~cm}$ : A Unicentre Randomized Trial with a 124-Month Median Follow-Up. Annals of Oncology, 10, 47-52.

https://doi.org/10.1023/A:1008337009350

[6] Gunduz, N., Fisher, B. and Saffer, E.A. (1979) Effect of Surgical Removal on the Growth and Kinetics of Residual Tumor. Cancer Research, 39, 3861-3865.

[7] Fisher, B., Gunduz, N. and Saffer, E.A. (1983) Influence of the Interval between Primary Tumor Removal and Chemotherapy on Kinetics and Growth of Metastases. Cancer Research, 43, 1488-1492.

[8] Prasad, S.R., Saini, S., Sumner, J.E., et al. (2003) Radiological Measurement of Breast Cancer Metastases to Lung and Liver: Comparison between WHO (Bidimensional) and RECIST (Unidimensional) Guidelines. Journal of Computer Assisted Tomography, 27, 380-384.https://doi.org/10.1097/00004728-200305000-00014

[9] Audretsch, W., Rezai, M., Kolotas, C., et al. (1994) Onco-Plastic Surgery: “Target” Vo- 
lume Reduction (BCT-Mastopexy), Lumpectomy, Reconstruction (BCT-Reconstruction), and Flap-Supported Operability in Breast Cancer. Proceedings of 2nd European Congress on Senology, Vienna, Austria, Bologna, October 2-6 1994, 139-157.

[10] Clough, K.B., Kaufman, G.J., Nos, C., Buccimazza, I. and Sarfati, I.M. (2010) Improving Breast Cancer Surgery: A Classification and Quadrant per Quadrant Atlas for Oncoplastic Surgery. Annals of Surgical Oncology, 17, 1375-1391. https://doi.org/10.1245/s10434-009-0792-y

[11] Bonadonna, E.G. (1992) Evolving Concepts in the Systemic Adjuvant Treatment of Breast Cancer. Cancer Research, 52, 2127-2137.

[12] Hennequin, C., Espie, M., Misset, J.L. and Maylin, C. (2004) Does Primary Chemotherapy Really Increase the Rate of Breast Conserving Treatments? Cancer Radiothérapie, 8, 48-53.

[13] Clough, K.B., Benyahi, D., Nos, C., Charles, C. and Sarfati, I. (2015) Oncoplastic Surgery: Pushing the Limits of Breast-Conserving Surgery. The Breast Journal, 21, 140-146. https://doi.org/10.1111/tbj.12372

[14] Emiroglu, M., Sert, I., Karaali, C., Aksoy, S.O., Ugurlu, L. and Aydın, C. (2016) The Effectiveness of Simultaneous Oncoplastic Breast Surgery in Patients with Locally Advanced Breast Cancer. Breast Cancer, 23, 463-470. https://doi.org/10.1007/s12282-015-0585-Z

[15] Specht, J. and Gralow, J.R. (2009) Neoadjuvant Chemotherapy for Locally Advanced Breast Cancer. Seminars in Radiation Oncology, 19, 222-228. https://doi.org/10.1016/j.semradonc.2009.05.001

[16] Vieira, R.A., Carrara, G.F., Neto, C.S., Morini, M.A., Brentani, M.M. and Folgueira, M.A. (2016) The Role of Oncoplastic Breast Conserving Treatment for Locally Advanced Breast Tumors. A Matching Case-Control Study. Annals of Medicine and Surgery, 10, 61-68. https://doi.org/10.1016/j.amsu.2016.08.001

[17] Barranger, E., Antomarchi, J., Chamorey, E., Cavrot, C., Flipo, B., Follana, P., Peyrottes, I., Chapellier, C., Ferrero, J.M. and Ihrai, T. (2015) Effect of Neoadjuvant Chemotherapy on the Surgical Treatment of Patients with Locally Advanced Breast Cancer Requiring Initial Mastectomy. Clinical Breast Cancer, 15, e231-e235. https://doi.org/10.1016/j.clbc.2015.03.001

[18] Matthes, A.G., Uemura, G., Kerr, L., Matthes, Â.C., Michelli, R.A., Folgueira, M.A. and da Costa Viera, R.A. (2012) Feasibility of Oncoplastic Techniques in the Surgical Management of Locally Advanced Breast Cancer. International Journal of Surgery, 10, 500-505. https://doi.org/10.1016/j.ijsu.2012.07.009

[19] Regaño, S., Hernanz, F., Ortega, E., Redondo-Figuero, C. and Gómez-Fleitas, M. (2009) Oncoplastic Techniques Extend Breast-Conserving Surgery to Patients with Neoadjuvant Chemotherapy Response Unfit for Conventional Techniques. World Journal of Surgery, 33, 2082-2086. https://doi.org/10.1007/s00268-009-0152-x

[20] Silverstein, M.J., Savalia, N., Khan, S. and Ryan, J. (2015) Extreme Oncoplasty: Breast Conservation for Patients Who Need Mastectomy. The Breast Journal, 21, 52-59. https://doi.org/10.1111/tbj.12356

[21] Clough, K.B., Lewis, J.S., Couturaud, B., Fitoussi, A., Nos, C. and Falcau, M.C. (2003) Oncoplastic Techniques Allow Extensive Resections for Breast-Conserving Therapy of Breast Carcinomas. Annals of Surgery, 1, 26-34. https://doi.org/10.1097/00000658-200301000-00005

[22] Bogusevicius, A., Cepuliene, D. and Sepetauskiene, E. (2014) The Integrated Evaluation of the Results of Oncoplastic Surgery for Locally Advanced Breast Cancer. The Breast Journal, 20, 53-60. https://doi.org/10.1111/tbj.12222 
[23] Papademetriou, K., Ardavanis, A. and Kountourakis, P. (2010) Neoadjuvant Therapy for Locally Advanced Breast Cancer: Focus on Chemotherapy and Biological Targeted Treatments' Armamentarium. Journal of Thoracic Disease, 2, 160-170.

[24] Antón, A., Ruiz, A., Plazaola, A., Calvo, L., Seguí, M.A., Santaballa, A., Munoz, M., Sanchez, P., Miguel, A., Carrasco, E. and Lao, J. (2011) Phase II Clinical Trial of Liposomal-Encapsulated Doxorubicin Citrate and Docetaxel, Associated with Trastuzumab, as Neoadjuvant Treatment in Stages II and IIIA HER2-Overexpressing Breast Cancer Patients. GEICAM 2003-03 Study. Annals of Oncology, 22, 74-79. https://doi.org/10.1093/annonc/mdq317

[25] Mohamed, E.I., Maximous, D.W., Aboziada, M.A., Abdel-Wanis, M.E. and Mikhail, N.N. (2010) Feasibility of Breast Conservation after Neoadjuvant Taxene Based Chemotherapy in Locally Advanced Breast Cancer: A Prospective Phase I Trial. Annals of Surgical Innovation and Research, 4, 5. https://doi.org/10.1186/1750-1164-4-5

[26] Mazouni, C., Naveau, A., Kane, A., Dunant, A., Garbay, J.R., Leymarie, N., Sarfati, B., Delaloge, S. and Rimareix, F. (2013) The Role of Oncoplastic Breast Surgery in the Management of Breast Cancer Treated with Primary Chemotherapy. Breast, 22, 1189-1193. https://doi.org/10.1016/j.breast.2013.07.055 